\title{
Adsorption behavior of arsenic onto protonated titanate nanotubes prepared via hydrothermal method
}

\author{
H.Y. Niu ${ }^{\text {a }}$, J.M. Wang ${ }^{\text {a }}$, Y.L. Shi ${ }^{a}$, Y.Q. Cai ${ }^{\mathrm{a}, *}$, F.S. Wei ${ }^{\mathrm{b}, *}$ \\ a State Key Laboratory of Environmental Chemistry and Ecotoxicology, Research Center for Eco-Environmental Science, Chinese Academy of Sciences, \\ P.O. Box 2871, Beijing 100085, China \\ ${ }^{\mathrm{b}}$ China National Environmental Monitoring Center, Beijing 100029, China
}

\section{A R T I C L E I N F O}

\section{Article history:}

Received 11 July 2008

Received in revised form 10 December 2008

Accepted 1 February 2009

Available online 12 February 2009

\section{Keywords:}

Titanate nanotubes

Nanosized titania particles

Arsenate

Arsenite

Adsorption

\begin{abstract}
A B S T R A C T
A mesoporous material, titanate nanotubes (TNs) with different surface areas (197-312 $\mathrm{m}^{2} \mathrm{~g}^{-1}$ ) and pore size diameters (2-6 nm) was synthesized by alkaline hydrothermal method. Their adsorption abilities to arsenic, the notoriously poisonous inorganic contaminant in groundwater were evaluated. Batch experiments showed that the adsorption of arsenate [As (V)] was more favored in acid solution, while the uptake of arsenite [As (III)] was preferred in alkaline solution. The maximum uptake of As (V) and As (III) calculated by Langmuir equation was $208 \mathrm{mg} \mathrm{g}^{-1}(\mathrm{pH} 3.0)$ and $60 \mathrm{mg} \mathrm{g}^{-1}(\mathrm{pH} 7.0)$ respectively achieved on TN (180-1) adsorbent ( $312 \mathrm{~m}^{2} \mathrm{~g}^{-1}$, internal diameter, $5 \mathrm{~nm}$ ), which was 33 and 10 times greater than those of nanosized titania particles $\left(40-50 \mathrm{~nm}, 15 \mathrm{mg} \mathrm{g}^{-1}\right)$. Silicate anions, phosphate and sulfate had little effect on arsenic adsorption onto TNs. In several real water samples, TNs still showed high uptake efficiency to arsenic at $\mathrm{pH}$ 7.0. More than $80 \%$ of As (III) and $95 \%$ of As (V) adsorbed on TNs could be desorbed with $1.0 \mathrm{M} \mathrm{NaOH}$ solution within $1 \mathrm{~h}$. Comparison study indicated that all the tubular titanate materials exhibited great adsorption capacity to arsenic regardless their surface areas. Since the equipment required for TNs synthesis is simple and cheap, and alkali solutions are reusable, TNs can be regarded as an efficient, low-cost adsorbent for the removal of arsenic.
\end{abstract}

(c) 2009 Elsevier Inc. All rights reserved.

\section{Introduction}

Arsenic, a common constituent of the earth's crust, has been the concern of the world for many years for its high toxicity and carcinogenicity [1-3]. Arsenic exists in natural water predominantly as inorganic arsenate, As (V) and arsenite, As (III) [3-7]. Elevated concentrations of arsenic are found in groundwater in many regions around the world, which are caused by the release of arsenic from As-bearing sediments or anthropogenic sources [8-10]. The World Health Organization (WHO) has revised the guideline for arsenic in drinking water from 50 to $10 \mu \mathrm{g} \mathrm{L}^{-1}$ considering its high toxicity.

Many different technologies have been developed to remove arsenic from water, such as adsorption, coagulation/precipitation, ion-exchange, and so on $[3,6,7]$. Among them, adsorption is considered to be one of the most promising technologies for its simplicity in operation and cost-effectivity [3]. Natural materials such as zeolite [11], natural iron ores [7,12,13], siderite [14] and red mud [15] have been examined intensively for arsenic removal. Although these materials are regarded as cheap and effective adsorbents,

\footnotetext{
* Corresponding authors. Tel.: +86 010 62849182; fax: +86 01062849239.

E-mail addresses: caiyaqi@rcees.ac.cn (Y.Q. Cai), weifs@public3.bta.net.cn (F.S. Wei)
}

there are several problems (their impurities, unknown stability and regeneration, low adsorption capacity and slow kinetics) associated with their use $[4,13,16]$. An ideal adsorbent should have suitable particle size or uniformly accessible pores, high surface area, and physical and/or chemical stability [4]. Recently, nanoscale metal oxides such as mesoporous alumina [4], $\mathrm{TiO}_{2}$ [8], and zero-valent iron [5] have attracted the attention of researchers, and they have shown great advantage towards arsenic removal.

Lately, titanate nanotube (TNs) with small diameters (less than $10 \mathrm{~nm}$ ) prepared by alkaline hydrothermal method is of particular interest for its potential application as hydrogen sensors, mesoporous catalyst supports, solar cell photosensitizers, ion-exchange materials and so forth $[17,18]$. This material can be easily fabricated by hydrothermal treatment of $\mathrm{TiO}_{2}$ (anatase, rutile brookite or amorphous forms) in highly concentrated $\mathrm{NaOH}$ aqueous solution at moderate temperatures $\left(90-180{ }^{\circ} \mathrm{C}\right)$. Compared with the template and sol-gel processes, this method is very simple with high quality and high yield (100\% efficiency) [18]. The equipment required is simple and alkali solutions are reusable, showing that this method has potential for large-scale industrial production [19]. TNs have large surface area $\left(300-400 \mathrm{~m}^{2} \mathrm{~g}^{-1}\right)$, and possess more functional hydroxyl groups on the surface [20]. Moreover, almost all protons of these $\mathrm{OH}$ groups can be easily exchanged with alkali or transition metal cations in aqueous solution [18,21]. 
Therefore, we assume that at $\mathrm{pH}<\mathrm{pH}_{\mathrm{pzc}}$ (point of zero charge), TNs would have great adsorption potential to arsenic anions. Then the purpose of our study is to investigate the adsorption feasibility of TNs for arsenic, and provide a new, efficient and low-cost adsorbent for arsenic removal.

\section{Experimental section}

\subsection{Chemical reagents}

All chemicals were analytical grade and purchased from Beijing Chemical Co. (Beijing, China). The arsenite and arsenate stock solution were prepared with deionized (DI) water using $\mathrm{NaAsO}_{2}$ and $\mathrm{Na}_{2} \mathrm{AsO}_{4} \cdot 7 \mathrm{H}_{2} \mathrm{O}$, respectively. Arsenic working solutions were freshly prepared by diluting stock solution with DI water. In some experiments, a tap water sample from our laboratory, a well water sample from the campus of China Agricultural University, and a river water sample from Jing Mi canal were used. The chemical compositions of water samples were summarized in Table S1. In all the samples the concentration of arsenic was below the detection limits $\left(0.5 \mathrm{ng} \mathrm{mL}^{-1}\right)$ determined by hydride generation-atomic fluorescence spectroscopy.

\subsection{Preparation of protonated titanate nanotubes}

The raw materials for TNs preparation included nanosized titania particle (TP, $40-50 \mathrm{~nm}, 15 \mathrm{~m}^{2} \mathrm{~g}^{-1}$ ) and sodium hydroxide. The surface area and pore size diameters of TNs were controlled by varying the reacting temperature and contact time of TP and $10 \mathrm{M} \mathrm{NaOH}$ solution. Generally, $3 \mathrm{~g}$ of titania was dispersed into $100 \mathrm{~mL}$ of $10 \mathrm{M} \mathrm{NaOH}$ solution, and remained in polytetrafluoroethylene autoclave to be heated at $110,130,150^{\circ} \mathrm{C}$ for $24 \mathrm{~h}$, or at $180^{\circ} \mathrm{C}$ for $10 \mathrm{~h}$ or $48 \mathrm{~h}$ respectively [the products were coded as TN (110), TN (130), TN (150), TN (180-1) and TN (180-2) respectively]. The white products were washed with DI water to neutral, and then soaked in $0.5 \mathrm{M}$ hydrochloric solution for $5 \mathrm{~h}$. During the soaking of the nanotubes in acid solution, the interlayer sodium ions were anticipated to be exchanged for the protons. Then the protonated titanate nanotubes were washed to $\mathrm{pH} 7$ with deionized water again. Finally, the products were dried at $100^{\circ} \mathrm{C}$.

\subsection{Batch adsorption test}

Batch experiments were performed to examine the adsorption behavior of arsenic on different adsorbents. Adsorption of arsenic as a function of $\mathrm{pH}$ onto protonated TNs was first examined in a series of experiments where the initial arsenic concentration was maintained constant (namely arsenare $5 \mathrm{mg} \mathrm{L}^{-1}$ and arsenite $25 \mathrm{mg} \mathrm{L}^{-1}$ ) at varying $\mathrm{pH}$ values ( $\mathrm{pH} \mathrm{2-11)}$ and then the optimum $\mathrm{pH}$ for adsorption was determined. But for TN (180-2) and TP, the initial concentration of arsenate and arsenite was $1 \mathrm{mg} \mathrm{L}^{-1}$. Adsorption isotherm studies were conducted with initial arsenate or arsenite concentrations ranging in $1-500 \mathrm{mg} \mathrm{L}^{-1}$ or $0.1-$ $200 \mathrm{mg} \mathrm{L}^{-1}$ at optimal $\mathrm{pH}$ in DI water. All batch tests were executed in $150 \mathrm{~mL}$ of glass bottles by taking $25 \mathrm{mg}$ (dry weight) of TNs or TP adsorbent together with $25 \mathrm{~mL}$ of arsenic solution. Reactions proceeded for $24 \mathrm{~h}$ at $25^{\circ} \mathrm{C}$ in a shaken water batch (200 rpm). The solution $\mathrm{pH}$ was adjusted with $1 \mathrm{M} \mathrm{HCl}$ and/or $1 \mathrm{M}$ Tris, the ionic strength was controlled to $0.02 \mathrm{M}$ with $1 \mathrm{M} \mathrm{NaCl}$ solution. However, for real water samples, the adsorption isotherms for arsenic species were carried out at $\mathrm{pH} 7.0$ without control of ionic strength. In order to test the effects of coexisting anions, the adsorption isotherms were also studied with 5,20 or $50 \mathrm{mg} \mathrm{L}^{-1}$ of $\mathrm{NaH}_{2} \mathrm{PO}_{4}, \mathrm{NaSiO}_{3}$ and $\mathrm{Na}_{2} \mathrm{SO}_{4}$ spiked into solution individually.
After mixing, the solid and solution were separated by centrifugation at $10,000 \mathrm{rpm}$ for $10 \mathrm{~min}$. Then a portion of supernatant was diluted to $5 \mathrm{~mL}$ with DI water and analyzed with hydride generation-atomic fluorescence spectroscopy (HG-AFS) with an AF-610A instrument (Beijing Ruili Analytical Instrument Co., Ltd. China). $\mathrm{HCl}$ solution $(2 \%, \mathrm{~V} / \mathrm{V})$ was used as carrying fluid. All samples were analyzed within $24 \mathrm{~h}$ after collection. Duplicate adsorption experiments were conducted, and averaged results were reported.

Desorption tests were studied using alkaline solution to examine whether the adsorbent could be recycled. The desorption solution was adjusted by $6 \mathrm{M} \mathrm{NaOH}$ solution, and for arsenate the $\mathrm{NaOH}$ concentration was in the range of $0.01-1.0 \mathrm{M}$ or $\mathrm{pH} 9.0$; for arsenite $\mathrm{NaOH}$ concentration was varied from $0.01 \mathrm{M}$ to $1.5 \mathrm{M}$. After adsorption of arsenic, the TNs were washed with $2 \mathrm{~mL}$ of DI water, then mixed with $2 \mathrm{~mL} \times 3$ of desorption solution. The mixture was shaken for $4 \mathrm{~h}$ followed by a centrifugation at $10,000 \mathrm{rpm}$ for separation. A kinetic study of desorption was conducted using $1.0 \mathrm{M} \mathrm{NaOH}$ solution.

\subsection{Adsorbents characterization}

An X-ray powder diffractometer (Rigaku III/B max) was used to analyze the crystalline structures of adsorbents. The radiation source was $\mathrm{Cu} \mathrm{K \alpha}$. The applied current was $30 \mathrm{~mA}$, and the voltage was $40 \mathrm{kV}$. During the analysis, the sample was scanned from $10^{\circ}$ to $100^{\circ}$ at a speed of $0.4^{\circ} / \mathrm{min}$. Transmission electron micrograph (TEM) images were recorded on a $\mathrm{H} 7500$ transmission electron micrograph (Hitachi, Japan) operating at $120 \mathrm{kV}$. The points of zero charge of the materials were determined with zetasizer 2000 apparatus (Malvern, United Kingdom). The specific surface areas of adsorbents were determined by the BET method with $\mathrm{N}_{2}$ gas (ASAP2000V3.01A; Micromeritics, Norcross, GA).

To detect the arsenic species adsorbed on the surface of the adsorbent after reaction with arsenite or arsenate, some selected samples were freeze-dried for further analysis using XPS collected on an ESCA-Lab-220i-XL spectrometer with monochromatic Al Ka radiation $(1486.6 \mathrm{eV})$. C1s peaks were used as an inner standard calibration peak at $284.7 \mathrm{eV}$. XPS data process and peak fitting was preformed using a nonlinear least-squares fitting program (XPSpeak software 4.1, Raymund W. M. Kwork).

\section{Results and discussion}

\subsection{Characterization of protonated TNs and TP}

TNs synthesized with hydrothermal method had well-defined and uniformly tubular morphology. Compared with carbon nanotubes, the titanate tubes were less adhesive to each other; the tube ends were released and kept open. As shown in Table 1 and Fig. 1, the surface areas (197-312 $\mathrm{m}^{2} \mathrm{~g}^{-1}$ ) and outer diameters of the TNs (5-13 nm) increased with the rising of heating temperature. However, for TN (180-2), the tubular structure disappeared, and nanosized fibers formed instead, which was consistent with the results reported by Lee et al. [22], Yuan and Su [23] and Bavykin et al. [24]. XRD results of TP showed that the raw material was a mixture of rutile and anatase (Fig. 2). As reported by other researchers $[22,25]$, though the TNs had been soaked in hydrochloric acid for a long time, sodium ions could not be substituted completely by protons. $\mathrm{Na}_{2} \mathrm{Ti}_{6} \mathrm{O}_{13}$ peaks in the XRD patterns of TNs were observed, while for nanofiber [TN (180-2)], distinct $\mathrm{Na}_{2} \mathrm{Ti}_{3} \mathrm{O}_{7}$ peaks were identified. The point of zero charge (PZC) of all materials was determined by their zeta potential in solution at different $\mathrm{pH}$. Compared with TP $\left(\mathrm{pH}_{\mathrm{PZC}} 6.3\right)$, the $\mathrm{pH}_{\mathrm{PZC}}$ value for TNs had shifted to a lower $\mathrm{pH}$ range $(\mathrm{pH} 4.8-5.4)$, and the nanofiber possessed the lowest value of $\mathrm{pH}_{\mathrm{PZC}}(\mathrm{pH} 4.5)$. Since all the hydroxyl 
Table 1

Points of zero charge, BET surface areas and size of raw materials (TP) and products (TNs).

\begin{tabular}{|c|c|c|c|c|}
\hline Material & PZC value $^{\mathrm{a}}$ & BET surface area $\left(\mathrm{m}^{2} \mathrm{~g}^{-1}\right)^{\mathrm{b}}$ & External diameter $(\mathrm{nm})$ & Internal diameter (nm) \\
\hline TP & pH 6.3 & 15.63 & $30-50$ & \\
\hline $\mathrm{TN}(110)$ & pH 5.4 & 197.05 & 5 & $2-3$ \\
\hline $\mathrm{TN}(130)$ & pH 5.3 & 311.26 & 7 & $3-4$ \\
\hline $\mathrm{TN}(150)$ & pH 5.1 & 279.78 & 11 & $5-6$ \\
\hline $\mathrm{TN}(180-1)$ & pH 4.8 & 312.59 & 13 & $4.5-5.5$ \\
\hline $\mathrm{TN}(180-2)$ & pH 4.5 & 37.83 & 44 & \\
\hline
\end{tabular}

a Points of zero charge of TP and TNs obtained by their zeta potentials in solution with $0.1 \mathrm{M} \mathrm{NaCl}$ at varied $\mathrm{pH}$.

b Determined from the Brunauer Emmett Teller (BET) equation.
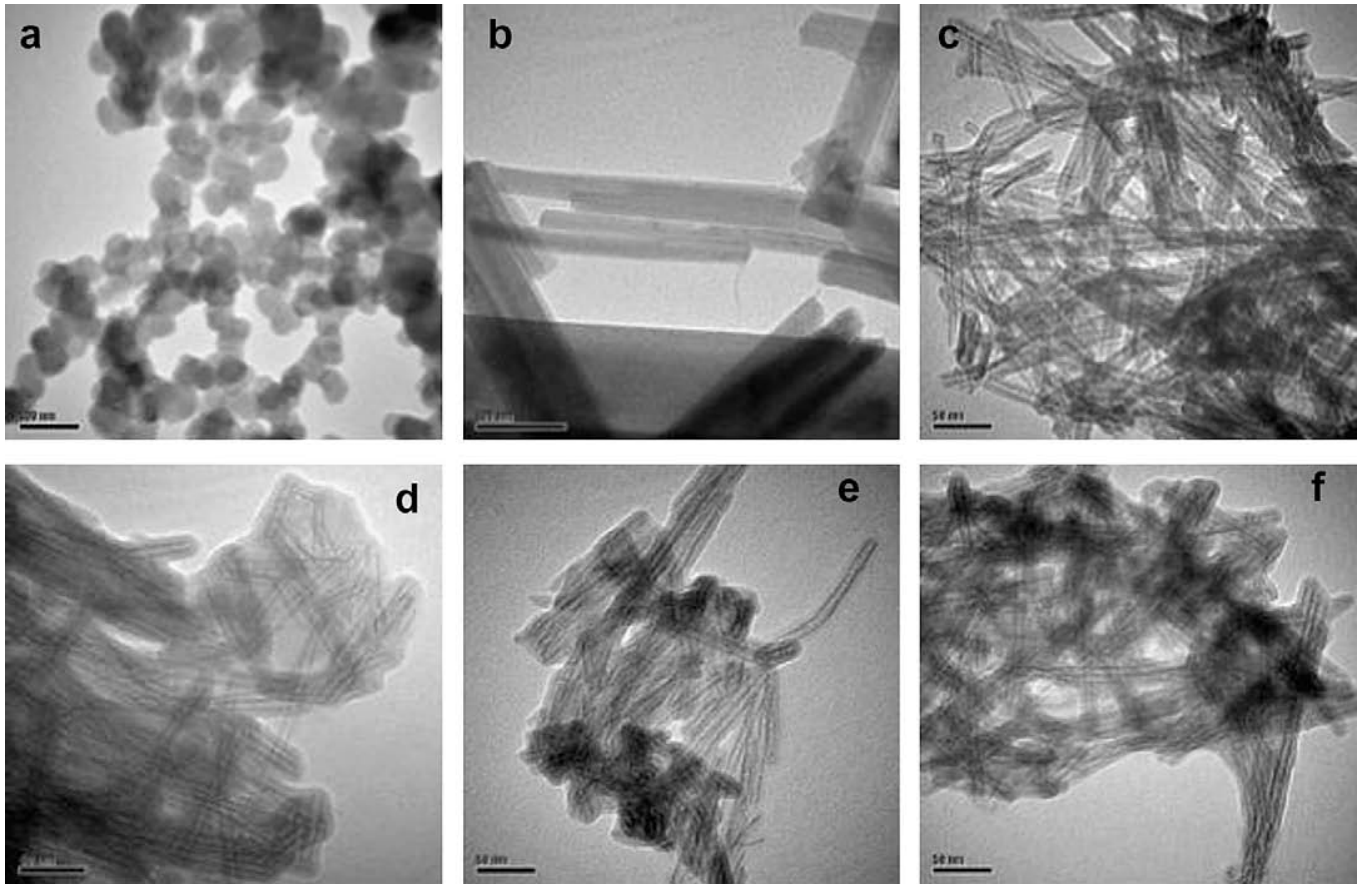

Fig. 1. TEM image of (a) TP, (b) TN (180-2), (c) TN (180-1), (d) TN (150), (e) TN (130) and (f) TN (110).

groups on TNs surface could be deprotonized, the lower $\mathrm{pH}_{\mathrm{PZC}}$ might mean more hydroxyl groups existing on the surface of nanofibers or TNs.

\subsection{Adsorption behavior and mechanism of arsenic on protonated TNs}

Arsenic adsorption reached equilibrium after $1 \mathrm{~h}$ of reaction with TP and TN (180-2). Possibly due to their tubular structure, longer contact time was demanded for the effective uptake of arsenic on TNs compared to TP and the nanofibers. The adsorption equilibrium of arsenic on all the tubular titanate was observed after $8 \mathrm{~h}$ of contact (Fig. 3). Arsenic adsorption was dependent on the initial solution $\mathrm{pH}$ (Fig. 4). All adsorbents showed similar adsorption trend towards arsenite and arsenate: the adsorption of arsenate was more favored in acid solution, and the uptake of arsenite was preferred in alkaline solution. The optimal $\mathrm{pH}$ ranges for arsenite and arsenate adsorption on TNs were $\mathrm{pH}$ 2.5-3.5 and $\mathrm{pH}$ 7.0-9.5 respectively, which were much wider than those of TP and TN (180-2). In the $\mathrm{pH}$ range of 6.0-7.5, the uptake of arsenate on TNs was greater than $70 \%$ with initial concentration of $25 \mathrm{mg} \mathrm{L}^{-1}$. For arsenite, $70 \%$ of As (III) still could be adsorbed at $\mathrm{pH} 10.5$. In the $\mathrm{pH}$ range of $2.5-11.5$, the predominant arsenate species exist as $\mathrm{H}_{2} \mathrm{AsO}_{4}^{-}$and $\mathrm{H}_{2} \mathrm{AsO}_{4}^{2}-$ [10]; and the main arsenite species is neutral $\mathrm{H}_{3} \mathrm{AsO}_{3}$ at $\mathrm{pH}<9.2$ [8]. The strong adsorption of arsenic at $\mathrm{pH}>\mathrm{pH}_{\mathrm{PZC}}$ might suggest that the arsenic species were adsorbed on TNs through surface complexation, rather than electrostatic interactions. During the adsorption of arsenite and arsenate, the equilibrium $\mathrm{pH}$ decreased obviously with higher initial $\mathrm{pH}$ indicating the deprotonation of arsenic enhanced by their reaction with adsorbents, which were helpful for their adsorption.

Zeta potentials of TN (180-1) in both the presence and absence of $1 \mathrm{mg} \mathrm{L}^{-1}$ arsenate or arsenite were described in Fig. 5. The adsorption of either arsenate or arsenite decreased the $\mathrm{pH}_{\mathrm{pzc}}$ of TN (180-1) to approximately 4.3 and 4.0. It was reported that the formation of outer-sphere surface complexes could not shift the $\mathrm{pH}_{\mathrm{pzc}}$ since there were no specific chemical reactions between the adsorbate and the surface that could change the surface charge. But the shift of $\mathrm{pH}_{\mathrm{pzc}}$ to a lower $\mathrm{pH}$ range could be caused by the formation of anionic negatively charged surface complexes [8]. These results implied that the adsorption of arsenic would be based on the negatively charged inner-sphere complexes between As (V) or As (III) and TNs.

To further understand the adsorption mechanism of arsenic and investigate the oxidation state of arsenic species adsorbed on the surface of TNs, XPS data of TN (180-1) before and after reaction with arsenic were studied. After reaction with As (V) and As (III), the $\mathrm{Ti}$ atom content decreased by $16 \%$ and $9.5 \%$ respectively (shown in Supplementary data, Table S2); while the content of oxygen atom increased instead which was attributed to the introduction of arsenic oxyanions or water molecule [26]. The XPS spec- 


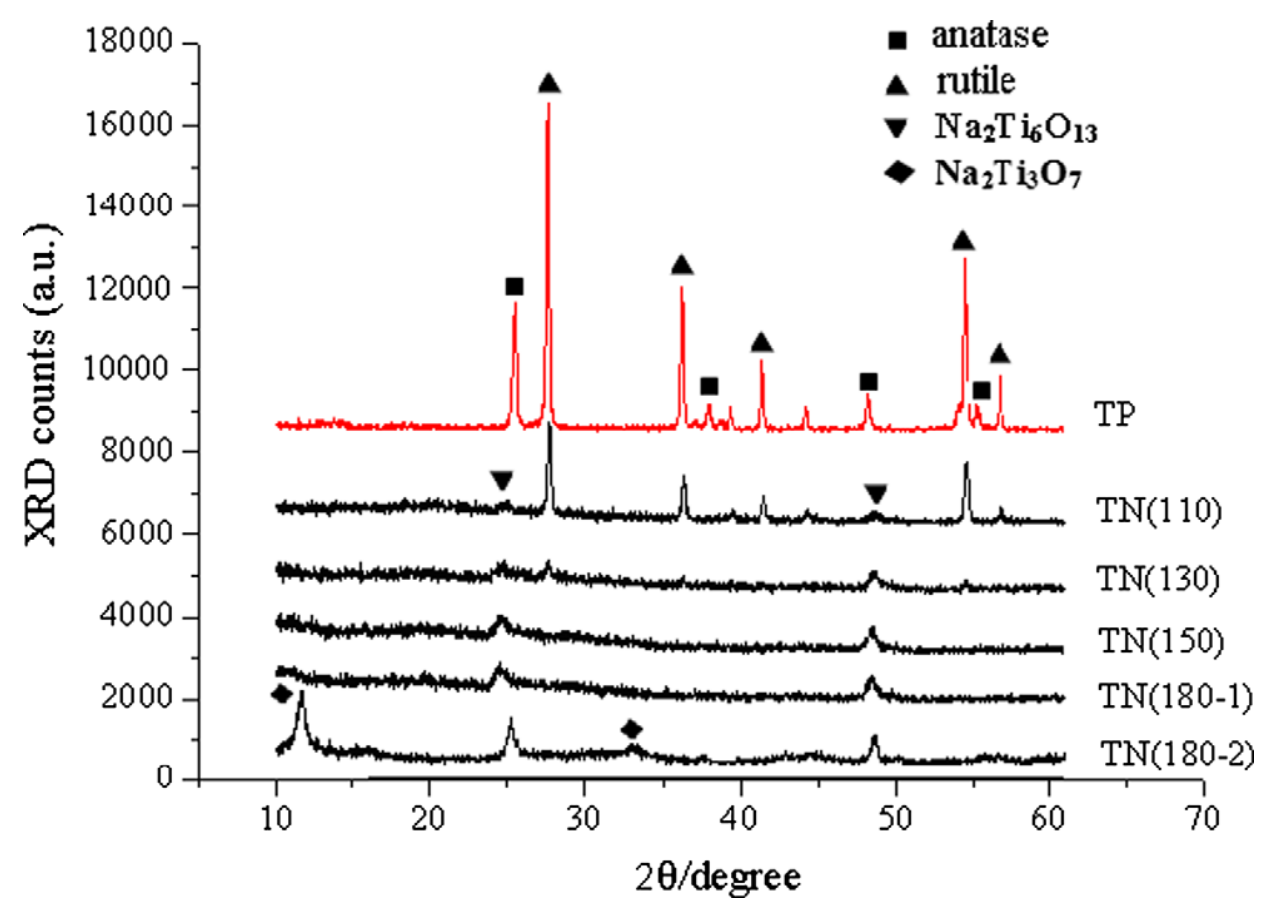

Fig. 2. XRD patterns of the nanosized titania particles (TP) and products obtained from hydrothermal $\mathrm{NaOH}$ treatment of TP at $110,130,150{ }^{\circ} \mathrm{C}$ for $24 \mathrm{~h}$, and $180^{\circ} \mathrm{C}$ for 10 or $48 \mathrm{~h}$ respectively [the products were coded as TN (110), TN (130), TN (150), TN (180-1) and TN (180-2), respectively].

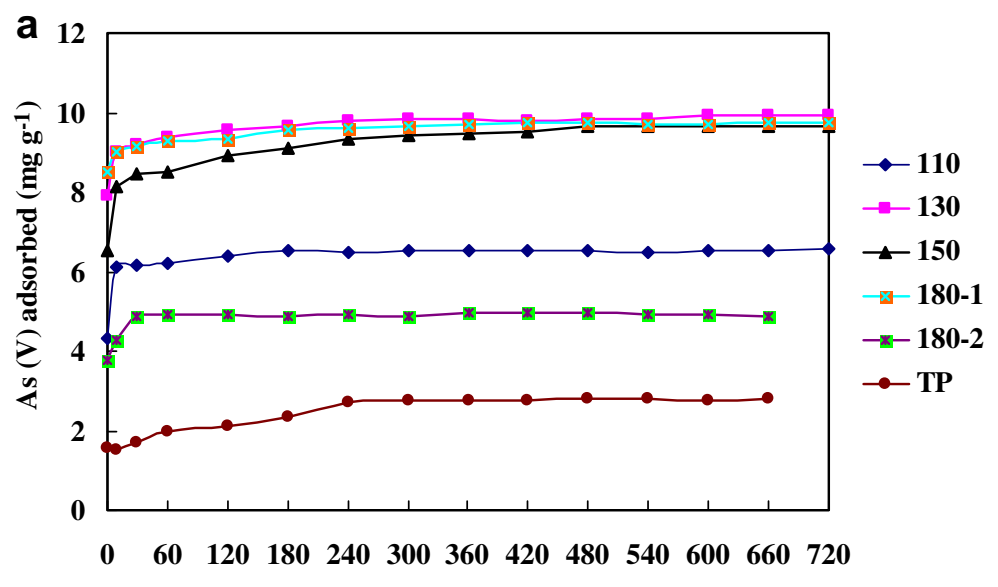

Time (min)

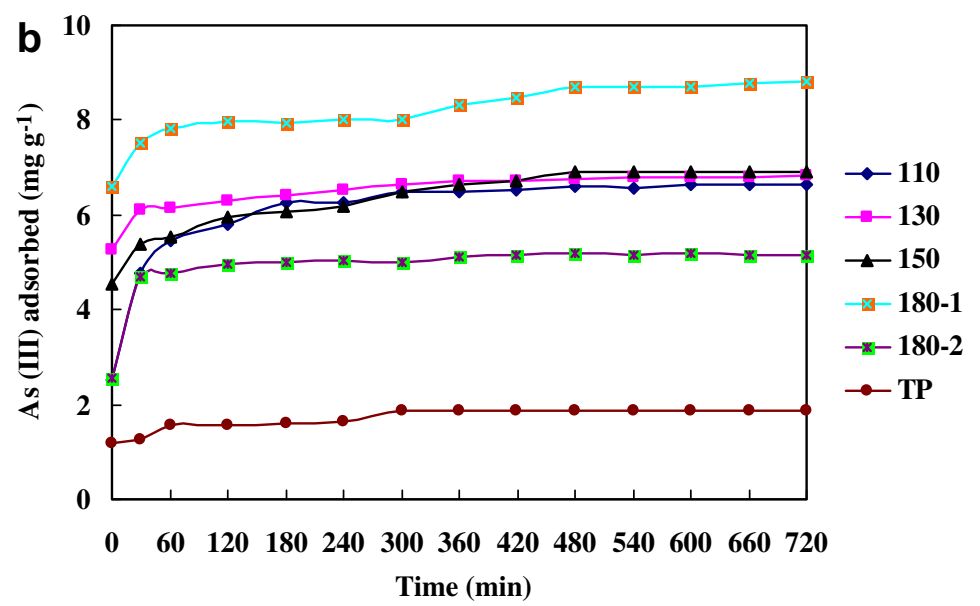

Fig. 3. Effect of contacting time on the adsorption of As (V) (a) and As (III) (b) onto different adsorbents. 

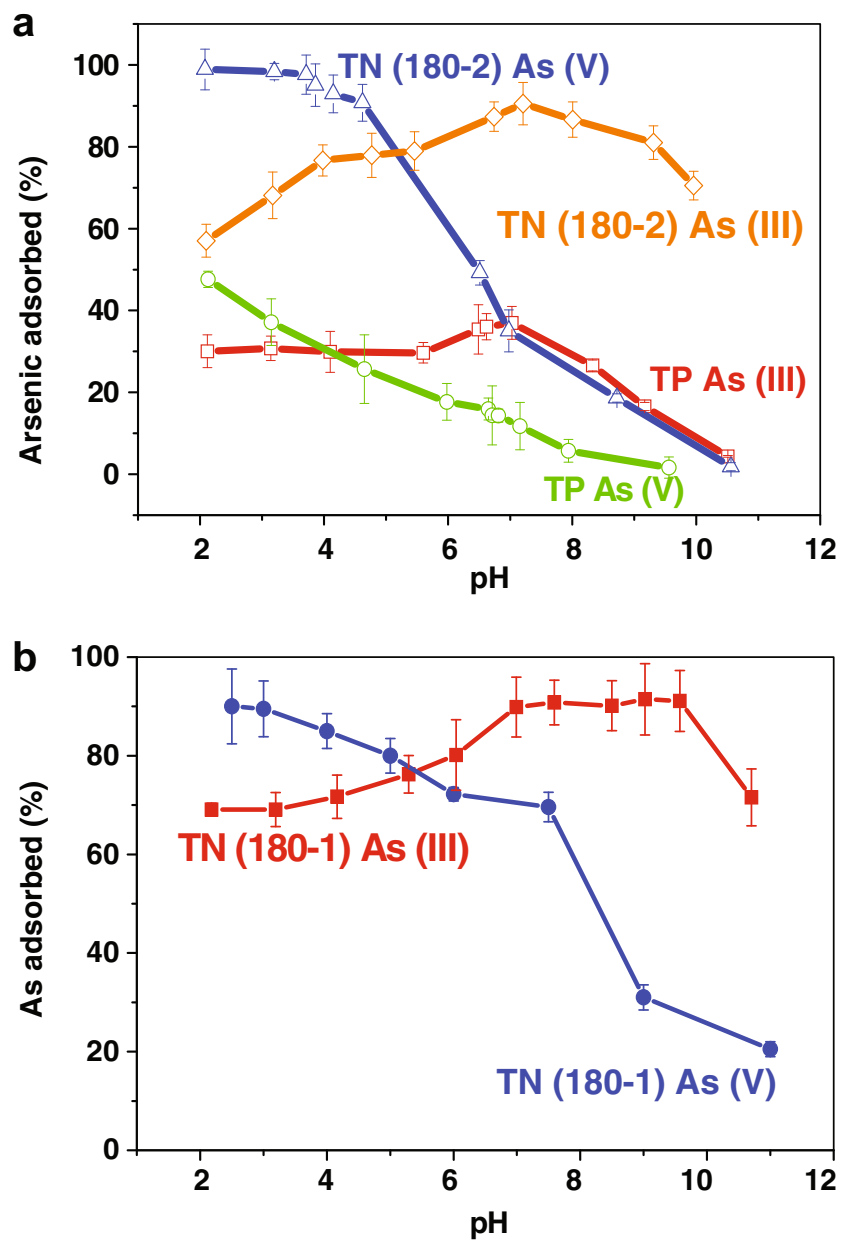

Fig. 4. Effect of solution $\mathrm{pH}$ on the adsorption of As (V) and As (III) onto TN (180-2), $\mathrm{TP}(\mathrm{a})$ and TN (180-1) (b). Initial concentration of arsenic: $1 \mathrm{mg} \mathrm{L}^{-1}$ for TN (180-2) and TP; for TN (180-1) As (V) $25 \mathrm{mg} \mathrm{L}^{-1}$, As (III) $5 \mathrm{mg} \mathrm{L}^{-1}$.

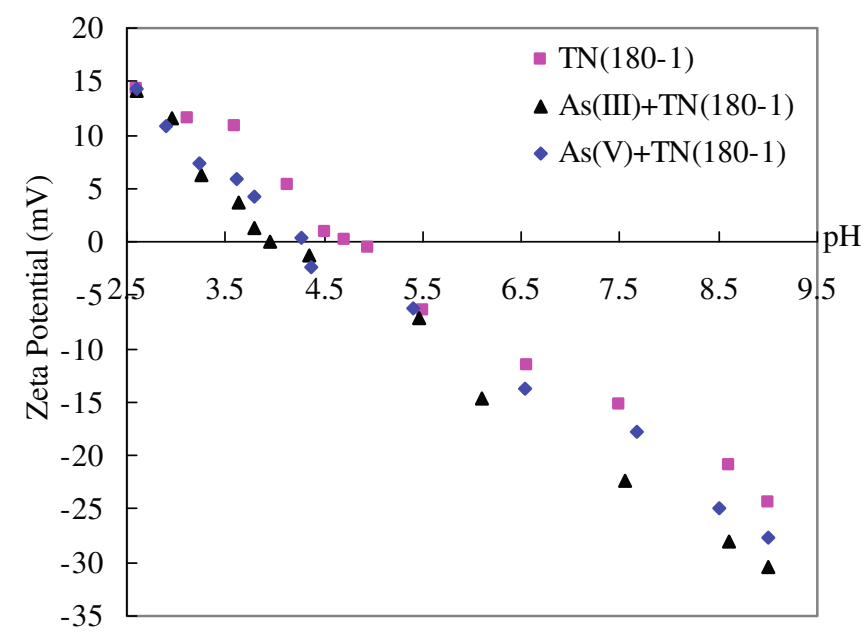

Fig. 5. Zeta potential of $0.6 \mathrm{~g} \mathrm{~L}^{-1} \mathrm{TN}(180-1)$ and $\mathrm{TN}(180-1)$ with $1 \mathrm{mg} \mathrm{L}^{-1}$ of As (V) or As (III) in $0.1 \mathrm{M} \mathrm{NaCl}$ solution.

tra of $01 \mathrm{~s}$ were illustrated in Fig. 6b, the peak of 01s spectra of surface complexes had shifted to a more negative binding energy for As (V) and As (III) adsorption (from 530.46 to 530.57 or $530.66 \mathrm{eV}$ respectively). After reaction with As (V), no increase of intensity of $01 \mathrm{~s}$ was observed; but $13 \%$ of enhancement of $01 \mathrm{~s}$ intensity was seen after adsorption of As (III), indicating the strong interactions between As (III) and O atoms [3,26]. In Fig. 6c and d, there was only one peak of As3d or As2p after uptake of arsenic, the binding energy of $44.6 \mathrm{eV}$ and $46.0 \mathrm{eV}$ should be ascribed to As (V)-O and As (III)-O respectively, which was accordant with the binding energy of arsenic after reaction with iron oxide [3]. It could be suggested that there was no As (III) oxidized into As (V) during the adsorption process.

\subsection{Equilibrium study}

The equilibrium adsorption isotherm data at different TNs adsorbents were analyzed using Freundlich and Langmuir models $[4,14]$.

$q=K_{F} C^{1 / n}$

$q=\frac{q_{m} K_{L} C}{1+K_{L} C}$

where $q_{m}\left(\mathrm{mg} \mathrm{g}^{-1}\right)$ is the maximum adsorption capacity, $q\left(\mathrm{mg} \mathrm{g}^{-1}\right)$ is the amount of adsorbed As, $C\left(\mathrm{mg} \mathrm{L}^{-1}\right)$ is the equilibrium solute (As) concentration, $K_{F}\left(\mathrm{~mL}^{1 / n} \mu \mathrm{g}^{1-1 / n}\right)$ and $n$ are the Freundlich constants, and $K_{L}$ is the Langmuir constant. The results of fitting Freundlich and Langmuir equations to isotherm curves were summarized in Table 2. Regression coefficients $\left(R^{2}\right)$ for different conditions were larger than 0.94 , indicating that both the models fit reasonably well with the arsenic adsorption. Compared with TP adsorbent, TNs exhibited good adsorption ability to arsenic. The adsorption capacity values obtained both from Langmuir and Freundlich equations showed that the adsorption capacity of TNs increased slightly with their surface area. The maximum adsorption of As (V) and As (III) were observed both on TN (180-1) adsorbent, and the maximal adsorption capacity for As (V) and As (III) calculated by Langmuir isotherm was 204.1 and $59.5 \mathrm{mg} \mathrm{g}^{-1}$ respectively at $25^{\circ} \mathrm{C}$, which were 33 and 10 times greater than those of TP. Compared with the nanocrystalline titanium dioxide [2] and Hombikat UV100 suspension [27] ( $\left.\geqslant 330 \mathrm{~m}^{2} \mathrm{~g}^{-1},<10 \mathrm{~nm}\right)$, the adsorption capacity of protonated titanate nanotubes was a little low, especially for As (III). It was reported that the interlay distance of multi-layers was about $0.7-0.8 \mathrm{~nm}$ [18] which was close to the radius of arsenate and arsenite ions $\left(\mathrm{HAsO}_{4}^{2-} 0.397 \mathrm{~nm}, \mathrm{HAsO}_{4}^{-} 0.416 \mathrm{~nm}\right.$, $\mathrm{H}_{3} \mathrm{AsO}_{4} 0.416 \mathrm{~nm}, \mathrm{HAsO}_{3}^{-} 0.48 \mathrm{~nm}, \mathrm{H}_{3} \mathrm{AsO}_{3} 0.48 \mathrm{~nm}$ ) [4]. Therefore the hydroxyl groups on the multiple intralayers might not be accessible to arsenic anions, resulting in the decrease of adsorption capacity to arsenic. Due to the photocatalytic property, the As (III) was usually adsorbed in the form of As (V) as nanocrystalline titanium dioxide was used, which was favorable for the adsorption of As (III). But no As (III) was oxidized into As (V) during the adsorption process in our study. However, the adsorption capacity of protonated TNs to arsenic was still comparable to some reported adsorbents such as mesoporous alumina [4].

The adsorption density at a particular residual concentration was calculated using [4]

$\Gamma=\frac{\left(C_{i}-C_{e}\right) V}{m S} \times 10^{-3}$

where $S$ is the surface area $\left(\mathrm{m}^{2} \mathrm{~g}^{-1}\right)$ of TNs adsorbents, $m$ is the amount (g) of TNs, $V$ is the volume of solution $(\mathrm{mL})$, and $C_{i}$ is the initial concentration of adsorbate $\left(\mathrm{mol} \mathrm{L}^{-1}\right)$, and $C_{e}$ is the equilibrium concentration of adsorbate $\left(\mathrm{mol} \mathrm{L}^{-1}\right)$. The maximum adsorption density $\left(\Gamma_{\max }\right)$ was obtained from the adsorption data. Interestingly, the adsorption density of arsenic on TNs and nanofibers decreased with the increase of surface area. The largest adsorption density for As (V) and As (III) was observed on either nanofiber TN (180-2) or TN (110), which might be caused by their different adsorption sites available on their surface. Although the surface area of TP was smaller than TN (180-2), this material still showed 

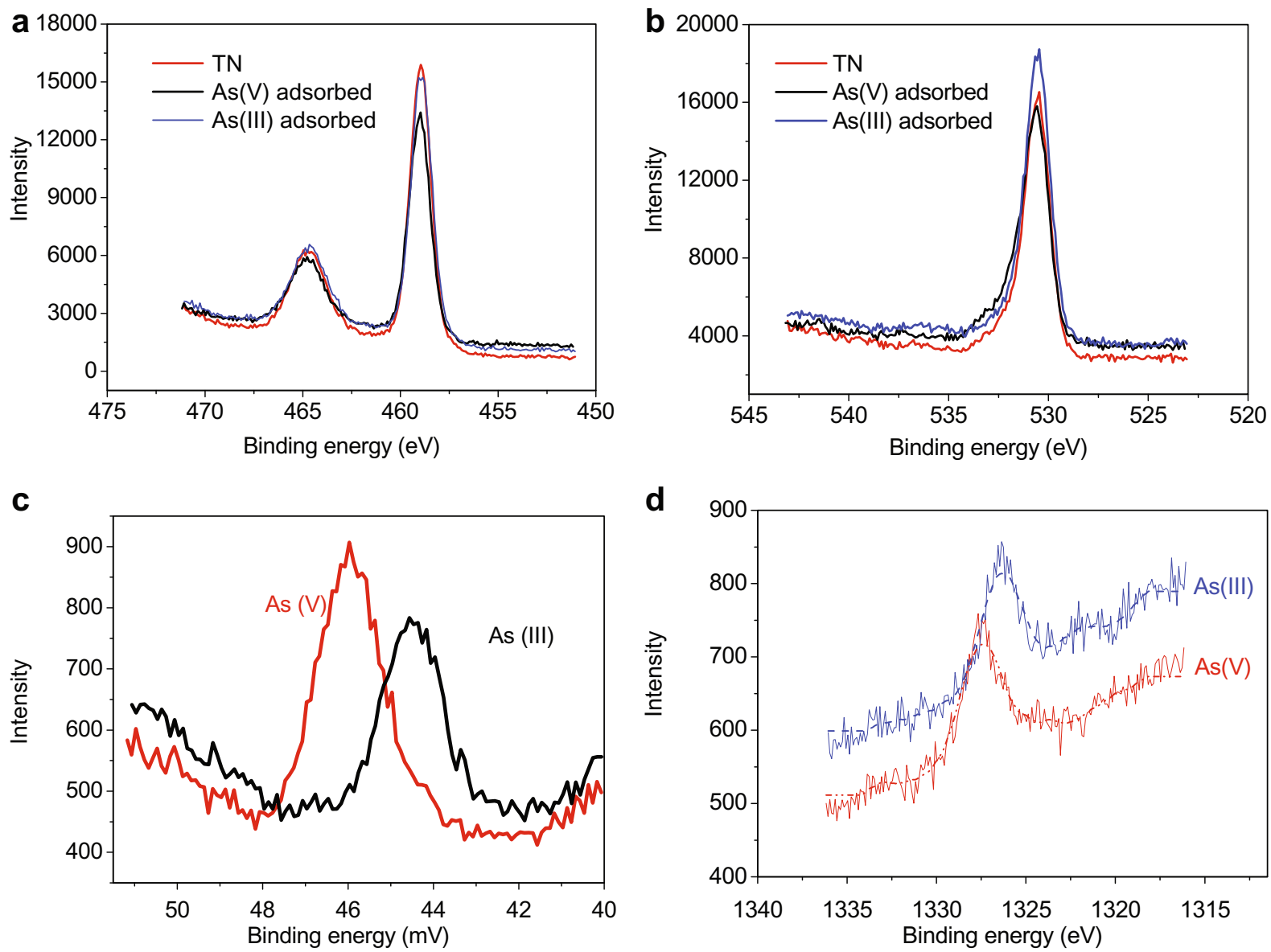

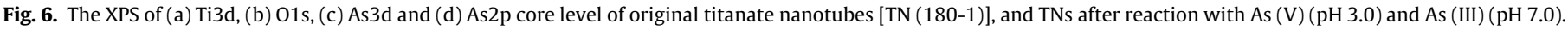

Table 2

Langmuir, Freundlich isotherms and adsorption density values for As (V) and As (III) onto TNs, TN (180-2) and TP .

\begin{tabular}{|c|c|c|c|c|c|c|c|c|}
\hline \multirow[t]{2}{*}{ Adsorbent } & & \multicolumn{3}{|c|}{ Langmuir } & \multicolumn{3}{|c|}{ Freundlich } & \multirow{2}{*}{$\begin{array}{l}\text { Adsorption density } \\
\Gamma_{\max }{ }^{\mathrm{e}}\end{array}$} \\
\hline & & $K^{\mathrm{b}}$ & $q_{m}{ }^{\mathrm{c}}$ & $R^{2}$ & $K_{F}^{\mathrm{d}}$ & $n$ & $R^{2}$ & \\
\hline \multirow[t]{6}{*}{ As $(V)$} & TN (110) & 0.019 & 188.7 & 0.983 & 20.7 & 3.00 & 0.977 & 13.06 \\
\hline & TN (130) & 0.027 & 204.1 & 0.997 & 25.2 & 3.09 & 0.977 & 8.94 \\
\hline & TN (150) & 0.023 & 192.3 & 0.997 & 23.9 & 3.01 & 0.993 & 9.22 \\
\hline & TN (180-1) & 0.019 & 204.1 & 0.994 & 23.0 & 2.97 & 0.995 & 8.89 \\
\hline & TN (180-2) & 0.148 & 28.7 & 0.976 & 5.15 & 2.46 & 0.944 & 10.26 \\
\hline & $\mathrm{TP}$ & 0.087 & 6.15 & 0.974 & 0.74 & 2.09 & 0.969 & 5.32 \\
\hline \multirow[t]{6}{*}{ As (III) } & TN (110) & 0.11 & 41.2 & 0.994 & 3.87 & 1.65 & 0.978 & 2.82 \\
\hline & TN (130) & 0.09 & 55.6 & 0.994 & 4.17 & 1.56 & 0.969 & 2.41 \\
\hline & TN (150) & 0.06 & 56.8 & 0.995 & 3.82 & 1.60 & 0.983 & 2.75 \\
\hline & TN $(180-1)$ & 0.08 & 59.5 & 0.992 & 4.90 & 1.80 & 0.977 & 2.57 \\
\hline & TN (180-2) & 0.09 & 16.4 & 0.973 & 2.35 & 2.37 & 0.993 & 3.77 \\
\hline & $\mathrm{TP}$ & 0.04 & 6.32 & 0.993 & 0.45 & 1.81 & 0.984 & 1.94 \\
\hline
\end{tabular}

a $\mathrm{As}(\mathrm{V})$ at $\mathrm{pH} 3.0$, As (III) at $\mathrm{pH} 7.0$, adsorbent, $1 \mathrm{~g} \mathrm{~L}^{-1}, 25^{\circ} \mathrm{C}$.

b $K\left(\mathrm{~L} \mathrm{mg}^{-1}\right)$.

c $q_{m}\left(\mathrm{mg} \mathrm{g}^{-1}\right)$.

d $K_{F}\left(\mathrm{~mL}^{1 / n} \mu \mathrm{g}^{1-1 / n}\right)$.

e $\Gamma_{\max },\left(\mathrm{mol} \mathrm{m}^{-2}\right)$ E-6.

the lowest adsorption density for arsenic among these adsorbents, indicating the binding sites density on TP surface was lower than TN (180-2). Additionally, the affinity of As (V) to the surface site of all the adsorbents was found to be 3-5 times as large as that of As (III).

It is reported that the maximum ion-exchange capacity for sodium ions can be as high as 1.1, expressed as a ratio between sodium and titanium atoms in the nanotubes ( $\mathrm{Na} / \mathrm{Ti}$ ratio). For some of transition metals, the ratio is in the range of 0.069-0.09
[18]. In our study, the As/Ti ratio was about 0.098 or 0.048 for As (V) and As (III) on TN (180-1) respectively (determined by XPS and EDX, Table S2).

\subsection{Effect of competing anions}

In a representative test, the effects of individual anions (silicate anions, phosphate and sulfate) on the adsorption capacity of TN (180-1), nanofiber or TP for As (V) and As (III) were investigated. 
And the spiked amount of each anion was coincident with their maximum concentration detected in water samples. Generally, the adsorption capacity of arsenate on TN (180-1) had decreased by $12.5 \%, 11 \%$ and $9 \%$ in the presence of phosphate, silicate anions and sulfate separately; while no evidently competitive effects on the adsorption of As (III) onto TN (180-1) were observed with these coexisting anions (Table 3). Similar result was reported by Bang [10] about the removal of arsenic by granular $\mathrm{TiO}_{2}$. But for TN (180-2) and TP, the adsorption capacity of arsenic was affected clearly in the presence of anions ( Table S3). With the spiked phosphate, silicate anions, the adsorption capacities of As (III) on nanofiber and TP were dropped to $60-70 \%$ or $65-85 \%$ respectively; and for As (V), a decrease of $35-40 \%$ or $50-60 \%$ of adsorption capacity were observed on the two adsorbents separately. These results probably meant that TNs also had high adsorption ability to phosphate, silicate or sulfate under the condition in our experiment.

\subsection{Desorption of arsenic}

To test the feasibility of TNs adsorbents to be regenerated after adsorption of arsenic, desorption study was carried out on TN (180-1) adsorbent. It was expected that increased concentration of $\mathrm{OH}^{-}$should compete greatly with the already adsorbed arsenate and arsenite on TNs, hence sodium hydroxide solution was used to desorb arsenic from adsorbent. Generally, desorption of the arsenic ions was more favored in strong alkaline solution. With $0.05 \mathrm{M}$ $\mathrm{NaOH}$ solution, $90 \%$ of the adsorbed As (V) was desorbed, and desorption percent could arrive at $95 \%$ if the concentration of $\mathrm{NaOH}$ was higher than $0.1 \mathrm{M}$. With regard to As (III), satisfactory desorption (85\%) of the adsorbed ions achieved with relatively higher concentration of $\mathrm{NaOH}(1.0 \mathrm{M} \mathrm{NaOH})$ (Fig. 7). Since the TNs were produced in $10 \mathrm{M} \mathrm{NaOH}$ solution and the tubes were more stable in base solution, desorption could be conducted in extreme alkaline solution to attain total desorption of adsorbed arsenic ions without destroy of the tubular structure of adsorbents. A kinetic study of desorption of adsorbed arsenic on TN (180-1) was performed using $1.0 \mathrm{M}$ of $\mathrm{NaOH}$ solution (Fig. 8). The desorption kinetics were much faster than the adsorption process. The desorption equilibrium for As (V) and As (III) was observed after contact $1 \mathrm{~h}$ and $3 \mathrm{~h}$ respectively with $\mathrm{NaOH}$ solution. Within $1 \mathrm{~h}$, $80 \%$ of arsenic (III) and $95 \%$ of arsenic (V) adsorbed to TNs could be desorbed.

\subsection{Adsorption of arsenic from water samples}

Batch studies on the adsorption of arsenic were conducted on tap water, groundwater and river water samples. In these samples, the level of As (V) and As (III) was below the detection limits of HG-

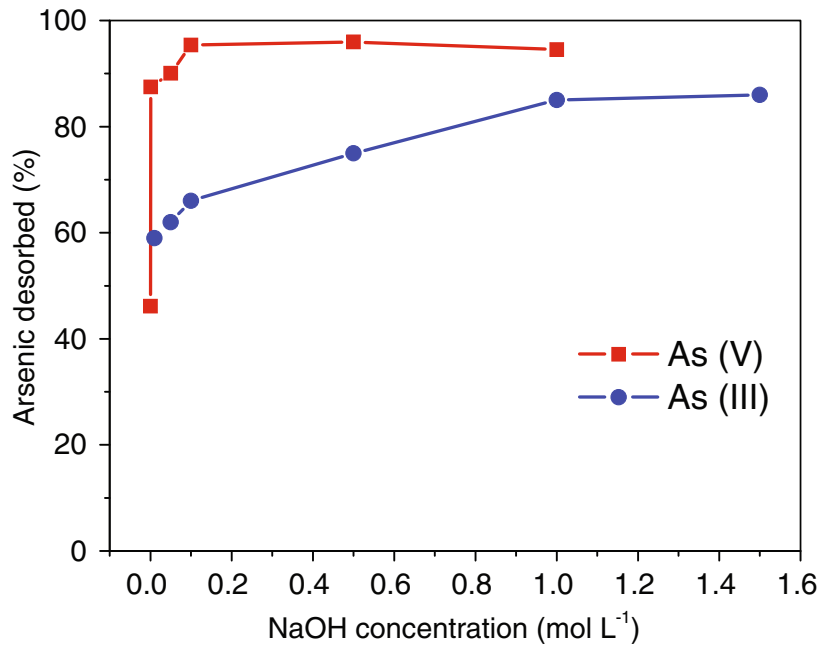

Fig. 7. Effect of $\mathrm{NaOH}$ concentration on desorption of As (V) and As (III).

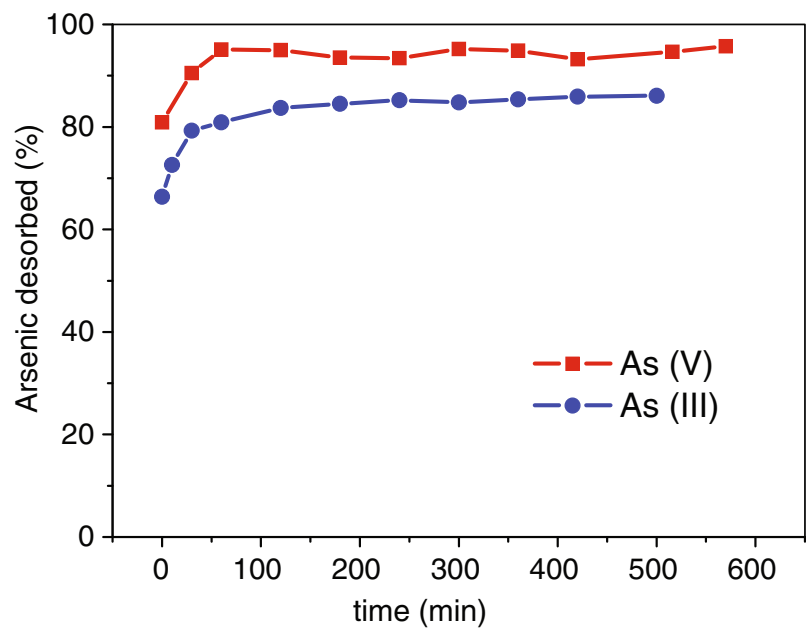

Fig. 8. Desorption kinetics for As (V) and As (III) with $1.0 \mathrm{M} \mathrm{NaOH}$ solution.

AFS, and the adsorption isotherms for arsenic were carried out at $\mathrm{pH} 7.0$ without control of ionic strength. For comparison, the adsorption capacity of As (V) on TNs at pH 7.0 in DI water was also determined. Consequently, an clearly decreased adsorption capacity of As (V) (Langmuir adsorption capacity, $82 \mathrm{mg} \mathrm{g}^{-1}$ ) was observed, but the reduced capacity was still comparable with those obtained by other metal oxide adsorbents, such as granular $\mathrm{TiO}_{2}$

Table 3

Langmuir and Freundlich parameters for As (V) and As (III) adsorption on TN (180-1) in the presence of anions ${ }^{\mathrm{a}}$.

\begin{tabular}{|c|c|c|c|c|c|c|c|}
\hline & & \multicolumn{3}{|l|}{ Langmuir } & \multicolumn{3}{|c|}{ Freundlich } \\
\hline & & $K\left(\mathrm{~L} \mathrm{mg}^{-1}\right)$ & $q_{m}\left(\mathrm{mg} \mathrm{g}^{-1}\right)$ & $R^{2}$ & $K_{F}$ & $n$ & $R^{2}$ \\
\hline \multirow[t]{4}{*}{ As (III) } & No $\mathrm{PO}_{4}$ or $\mathrm{SiO}_{2}$ or $\mathrm{SO}_{4}^{2-}$ & 0.08 & 59.5 & 0.992 & 4.90 & 1.80 & 0.977 \\
\hline & $\mathrm{PO}_{4}^{\mathrm{b}}$ & 0.058 & 56.8 & 0.995 & 4.34 & 1.89 & 0.993 \\
\hline & $\mathrm{SiO}_{2}{ }^{\mathrm{c}}$ & 0.049 & 57.8 & 0.998 & 4.37 & 1.95 & 0.999 \\
\hline & $\mathrm{SO}_{4}^{2-\mathrm{d}}$ & 0.056 & 57.5 & 0.999 & 4.40 & 1.90 & 0.994 \\
\hline \multirow[t]{4}{*}{ As $(\mathrm{V})$} & No no $\mathrm{PO}_{4}$ or $\mathrm{SiO}_{2}$ or $\mathrm{SO}_{4}^{2-}$ & 0.019 & 204.1 & 0.994 & 23.0 & 2.97 & 0.995 \\
\hline & $\mathrm{PO}_{4}$ & 0.015 & 178.6 & 0.998 & 9.01 & 2.03 & 0.988 \\
\hline & $\mathrm{SiO}_{2}$ & 0.017 & 181.8 & 0.996 & 11.2 & 2.18 & 0.984 \\
\hline & $\mathrm{SO}_{4}^{2-}$ & 0.030 & 185.2 & 0.998 & 16.2 & 2.32 & 0.999 \\
\hline
\end{tabular}

\footnotetext{
a As (V), pH 3.0; As (III), pH 7.0; TN (180-1), $1 \mathrm{~g} \mathrm{~L}^{-1}$.

b $5 \mathrm{mg} \mathrm{L}^{-1}$.

c $20 \mathrm{mg} \mathrm{L}^{-1}$.

d $50 \mathrm{mg} \mathrm{L}^{-1}$.
} 

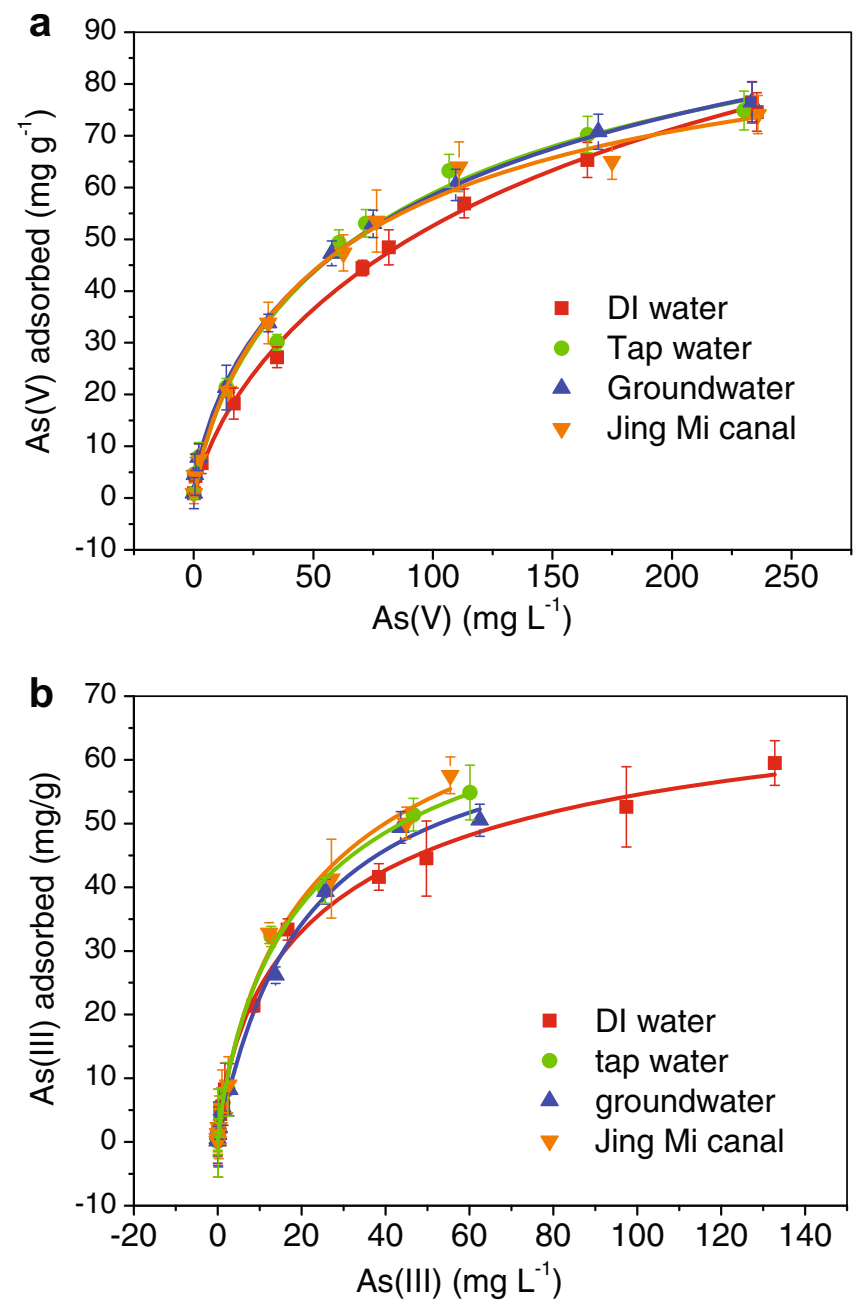

Fig. 9. Langmuir isotherms for (a) As (V), and (b) As (III) adsorption on TN (180-1) in several real water samples, $\mathrm{pH} 7.0$; TN (180-1), $1 \mathrm{~g} \mathrm{~L}^{-1}$

[10] and metal modified MCM-41 [28] in neutral solution. In these environmental water samples, the adsorption efficiency of spiked As (V) and As (III) by TNs was as high as those obtained in DI water (Fig. 9) and the maximal uptake capacity for As (V) and As (III) was 81.3 and $60 \mathrm{mg} \mathrm{g}^{-1}$ respectively. Meanwhile, arsenite, the more toxic species of arsenic, could be removed with $95-100 \%$ efficiency in water samples at an initial arsenite concentration of $\leqslant 500 \mu \mathrm{g} \mathrm{L}^{-1}$ with the residual arsenic concentration less than $10 \mu \mathrm{g} \mathrm{L}{ }^{-1}$.

\section{Conclusion}

The titanate nanotubes with high surface area, open tube end and uniform tubular size have exhibited fast uptake rate and high adsorption capacity to inorganic arsenic. The coexisting anions in solution show little competition effect on the adsorption of arsenic onto TNs. The adsorbed arsenic can be desorbed with $\mathrm{NaOH}$ solution efficiently and quickly. Moreover, TNs manifest reasonable uptake efficiency to arsenic at $\mathrm{pH} 7.0$ in several real water samples. Anyway, the results presented here have suggested the potential of TNs as an efficient material for the treatment of arsenic. However, more experimental work is required to evaluate the possible use of TNs under continuous flow conditions, which is under progress in our lab.

\section{Acknowledgments}

This work was jointly supported by National Basic Research Program of China (2009CB421605); the National Natural Science Foundation of China (20621703, 20577058, 20877079).

\section{Appendix. Supplementary data}

Supplementary data associated with this article can be found, in the online version, at doi:10.1016/j.micromeso.2009.02.005.

\section{References}

[1] D. Mohan, C.U. Pittman Jr., J. Hazard. Mater. 142 (2007) 1.

[2] M.E. Pena, G.P. Korfiatis, M. Patel, L. Lippincott, X.G. Meng, Water Res. 39 (2005) 2327.

[3] G.S. Zhang, J.H. Qu, H.J. Liu, R.P. Liu, G.T. Li, Environ. Sci. Technol. 41 (2007) 4613.

[4] Y. Kim, C. Kim, I. Choi, S. Rengaraj, J. Yi, Environ. Sci. Technol. 38 (2004) 924.

[5] S.R. Kanel, B. Manning, L. Charlet, H. Choi, Environ. Sci. Technol. 39 (2005) 1291.

[6] M.A. Ferguson, M.R. Hoffmann, J.G. Hering, Environ. Sci. Technol. 39 (2005) 1880.

[7] B.A. Manning, M.L. Hunt, C. Amrhein, J.A. Yarmoff, Environ. Sci. Technol. 36 (2002) 5455.

[8] M. Pena, X.G. Meng, G.P. Korfiatis, C.Y. Jing, Environ. Sci. Technol. 40 (2006) 1257.

[9] X.J. Guo, Y.H. Du, F.H. Chen, H.S. Park, Y.N. Xie, J. Colloid Interface Sci. 314 (2007) 427.

[10] S. Bang, M. Patel, L. Lippincott, X.G. Meng, Chemosphere 60 (2005) 389.

[11] M.S. Onyango, H. Matsuda, T. Ogada, J. Chem. Eng. Jpn. 36 (2003) 477.

[12] K. Tyrovola, E. Peroulaki, N.P. Nikolaidis, Eur. J. Soil Biol. 43 (2007) 356.

[13] E. Deschamps, V.S.T. Ciminelli, W.H. Höll, Water Res. 39 (2005) 5212.

[14] H.M. Guo, D. Stüben, Z. Berner, J. Collid Interface Sci. 315 (2007) 47.

[15] H. Genc-Fuhrman, J.C. Tjell, D. McConchie, Environ. Sci. Technol. 38 (2004) 2428.

[16] J.S. Zhang, R. Stanforth, Langmuir 21 (2005) 2895

[17] D.V. Bavykin, J.M. Friedrich, A.A. Lapkin, F.C. Walsh, Chem. Mater. 18 (2006) 1124.

[18] D.V. Bavykin, J.M. Friedrich, F.C. Walsh, Adv. Mater. 18 (2006) 2807.

[19] X.M. Sun, Y.D. Li, Chem. Eur. J. 9 (2003) 2229.

[20] A.H. Liu, M.D. Wei, I. Honma, H.S. Zhou, Anal. Chem. 77 (2005) 8068.

[21] D.V. Bavykin, A.A. Lapkin, P.K. Plucinski, J.M. Friedrich, F.C. Walsh, J. Phys. Chem. B 109 (2005) 19422

[22] C.K. Lee, K.S. Lin, C.F. Wu, M.D. Lyu, C.C. Lo, J. Hazard. Mater. 150 (2008) 494.

[23] Z.Y. Yuan, B.L. Su, Colloids Surf. A 241 (2004) 173.

[24] D.V. Bavykin, V.N. Parmon, A.A. Lapkin, F.C. Walsh, J. Mater. Chem. 14 (2004) 3370 .

[25] E. Morgado Jr., M.A.S. de Abreu, O.R.C. Pravia, B.A. Marinkovic, P.M. Jardim, F.C. Rizzo, A.S. Araújo, Solid State Sci. 8 (2006) 888

[26] Y. Zhang, M. Yang, X.M. Dou, H. He, D.S. Wang, Environ. Sci. Technol. 39 (2005) 7426.

[27] P.K. Dutta, A.K. Ray, V.K. Sharma, F.J. Millero, J. Colloid Interface Sci. 278 (2004) 270.

[28] H. Yoshitake, T. Yokoi, T. Tatsumi, Chem. Mater. 15 (2003) 1713. 